\title{
TINGKAT PENDIDIKAN DAN MASA KERJA TERHADAP KINERJA KARYAWAN PT PRIMA MAKMUR ROTOKEMINDO
}

\author{
Yudha Supriyatna \\ $\underline{\text { Yudha69prawira@gmail.com }}$
}

Fakultas Ekonomi dan Bisnis, Universitas Serang Raya

\begin{abstract}
ABSTRAK
Penelitian ini bertujuan untuk mengetahui pengaruh tingkat pendidikan dan masa kerja terhadap kinerja karyawan PT Prima Makmur Rotokemindon. Dalam penelitian ini menggunakan pendekatan kuantitatif dengan teknik pengumpulan data studi membagikan kuesioner kepada responden.Adapun sampel terpilih sebanyak 71 orang. Dan yang dijadikan objek dalam penelitian ini adalah karyawan pada PT Prima Makmur Rotokemindo sedangkan yang menjadi objek dalam penelitian ini adalah tingkat pendidikan, masa kerja, dan kinerja karyawan. Data dianalisis dengan analisis regresi berganda dengan SPSS 23.0 for windows yang meliputi uji $t$ dan uji F.Hasil penelitian ini adalah : (1) Tingkat Pendidikan berpengaruh signifikan terhadap Kinerja karyawan PT Prima Makmur rotokemindo. (2)Masa kerja berpengaruh signifikan terhadap Kinerja Karyawan PT Prima Makmur Rotokemindo. (3) Tingkat Pendidikan dan Masa kerja secara simultan berpengaruh signifikan terhadap Kinerja Karywan PT Prima Makmur Rotokemindo.
\end{abstract}

Kata Kunci: Tingkat Pendidikan, Masa Kerja Karyawan, dan Kinerja karyawan.

\section{ABSTRACT}

This study aims to determine the effect of education level and tenure on the performance of PT Prima Makmur Rotokemindon employees. In this study using a quantitative approach with study data collection techniques to distribute questionnaires to respondents. The selected sample is 71 people. And the object used in this study is employees at PT Prima Makmur Rotokemindo while the objects in this study are the level of education, years of service, and employee performance. Data were analyzed by multiple regression analysis with SPSS 23.0 for Windows which included t test and F test. The results of this study were: (1) The level of education had a significant effect on the performance of PT Prima Makmur rotokemindo employees. (2) The period of work has a significant effect 
on the Employee Performance of PT Prima Makmur Rotokemindo. (3) The level of education and working period simultaneously have a significant effect on the performance of PT Prima Makmur Rotokemindo.

Keywords: Level of Education, Employee Work Period, and Employee Performance

\section{PENDAHULUAN}

Dalam sebuah perusahaan, sumber daya manusia menjadi sorotan maupun tumpuan bagi perusahaan untuk tetap dapat bertahan. Sumber daya manusia merupakan peran utama dalam setiap kegiatan perusahaan. Walaupun banyaknya sarana dan prasarana serta sumber daya, tanpa dukungan sumber daya manusia kegiatan perusahaan tidak akan berjalan dengan baik. Dengan demikian sumber daya manusia merupakan kunci pokok yang harus diperhatikan dalam hal kebutuhannya. Sumber daya manusia yang memiliki kinerja yang tinggi akan menentukan keberhasilan pelaksanaan kegiatan perusahaan.

Adanya kinerja yang tinggi, diharapkan tujuan perusahaan dapat tercapai, sebaliknya perusahan susah atau bahkan tidak dapat tercapai bila karyawan tidak memiliki kinerja dalam melaksanakan tugas sesuai dengan tanggung jawab yang diberikan. Dan yang mempengaruhi seberapa banyak mereka memberikan konstribusi kepada organisasi yang dianataranya adalah kualitas pekerjaan, kejujuran karyawan, inisiatif, kehadiran dan pengetahuan tentang pekerjan, sikap dan tanggung jawab, kerja sama dan keandalan.Di dalam melaksanakan kegiatan kerja, karyawan secara mutlak memerlukan tingkat pendidikan dan masa kerja , apabila variable tersebut telah terpenuhi maka tingkat kinerja karyawan diharapkan meningkat.

Tanggung jawab karyawan seharusnya sesuai dengan keahliannya agar kinerja karyawan sesuai dengan standarisasi yang di butuhkan perusahaan. Perusahaan akan memperoleh output yang baik yang dihasilkan sesuai dengan keahliannya.

Untuk mencapai sarana dan tujuan yang telah ditetapkan perusahaan, pihak manajemen PT Prima Makmur Rotokemindo menerapkan strategi - strategi yang bertujuan untuk dapat meningkatkan kinerja keuangan dan bisnis serta meningkatkan performasi perusahaan baik dalam profabilitas maupun keberhasilan. Guna untuk meningkatkan kinerja karyawan terhadap perusahaan maka diperlukan perhatian dari pihak manajemen, diharapkan pemegang kendali manajemen menyadari serta memenuhi akan keinginan dan kebutuhan para karyawan demi kelacaran operasional perusahaan. 
Berdasarkan uraian yang telah dikemukakan tersebut diatas, maka masalah yang dapat dirumuskan adalah sebagai berikut :

1. Apakah Tingkat pendidikan mempengaruhi kinerja karywan PT Prima Makmur Rotokemindo ?

2. Apakah Masa kerja karyawan mempengaruhi kinerja karyawan PT Prima Makmur Rotokemindo ?

3. Apakah Tingkat pendidikan dan Masa kerja mempengaruhi Kinerja karyawan PT Prima Makmur Rotokemindo?

\section{TINJAUAN PUSTAKA}

\section{Tingkat Pendidikan}

Sedangkan Hariandja (dalam Indri Novi, 2016) menyatakan bahwa tingkat pendidikan sesorang karayawan dapat meningkatkan daya saing perusahaan dan memperbaiki kinerja perusahaan.

Adapun menurut UU Sistem Pendidikan Nasional No.20 Tahun 2003 (Indri Novi, 2016) tingkat pendidikan terdiri dari jenjang pendidikan dan kesesuaian jurusan (pendidikan formal). Jenjang pendidikan adalah tahapan pendidikan yang di tetapkan berdasarkan tingkat perkembangan peserta didik, tujuan yang akan dicapai dan kemampuan yang akan dikembangkan terdiri dari :

a. Pendidikan dasar

b. Pendidikan menengah

c. Pendidikan tinggi

Menurut Tirtarahardja (dalam Nur Afni, 2017 :17), jenis tingkat pendidikan terdiri dari :

1. Jenjang pendidikan adalah tahapan pendidikan yang ditetapkan berdasarkan tingkat perkembangan peserta didik, tujuan yang akan dicapai dan kemampuan yang dikembangkan.

2. Kesesuaian jurusan adalah sebelum pegawai direkrut terlebih dahulu perusahaan menganalisis tingkat pendidikan dan kesesuaian jurusan pendidikan pegawai tersebut agar nantinya dapat ditempatkan pada posisi jabatan yang sesuai dengan kualifikasi pendidikannya tersebut. Dengan demikian karyawan dapat memberikan kinerja yang baik bagi perusahaan. 
3. Kompetensi adalah pengetahuan, penguasaan terhadap tugas, keterampilan dan nilai-nilai dasar yang direfleksikan dalam kebiasaan berfikir dan bertindak.

Dengan berbekal tingkat pendidikan yang dimiliki seseorang individu akan mampu menghadapi persoalan-persoalan yang dihadapinya berkaitan dengan profesinya, dengan pendidikan yang tinggi seorang individu secara tidak langsung akan memberikan konstribusi lebih bagi organisasi untuk lebih berkembang lagi dimasa yang akan datang, karena akan sulit bagi seorang individu untuk dapat membuat organisasai berkembang tanpa pendidikan dan pengetahuan yang cukup pada latar belakang bidang pekerjaannya.

\section{Masa Kerja}

Menurut Aldy Hardikriyawan (2015) masa kerja dapat diartikan sebagai jumlah waktu seoarang pegawai untuk bekerja pada sebuah perusahaan atau instansi. Dalam kaitannya dengan pegawai , masa kerja didefinisikan sebagai lama (jumlah tahun) bagi pegawai mengabdi kepada institusi atau perusahaan.

Secara umum masa kerja adalah tingkat pengalaman kerja karyawan yang dihitung dari lama bekerja pada bidang tertentu dan pada lingkup tertentu.Hal ini diartikan jika seorang karyawan yang telah mempunyai jangka waktu yang relatif masa kerja tidak akan mengalami kesulitan yang berarti dalam melakukan proses produksi dalam kerja.Masa kerja seorang karyawan memungkinkan minimnya terjadi kesalahan-kesalahan yang dapat dilakukan sehingga tidak mengganggu dalam proses produksinya sehingga perusahaan tetap memenuhi target perusahaan.

Indikator-indikator masa kerja menurut (Luh Maya Susanti, 2014) adalah sebagai berikut :

1) Pengalaman kerja

2) Tingkat Pengetahuan dan ketrampilan yang dimiliki

3) Penguasaan terhadap pekerjaan

\section{Kinerja Karyawan}

Terdapat beberapa pengertian kinerja karyawan, diantaranya adalah Suparyadi (2015:55) kinerja karyawan yaitu masalah yang sentral dalam kehidupan sebuah organisasi karena sebuah organisasi atau perusahaan akan mampu mencapai tujuan atau tidak, sangat tergantung pada sebaik apa kinerja yang ditunjukan oleh para karyawannya. 
Menurut Mathis dan Jockson (Helena,2016:40) dimensi dari kinerja karyawan adalah :

1. Kuantitas

Merupakan jumlah yang dihasilkan dan dinyatakan dalam istilah seperti jumlah unit, jumlah siklus aktivitas yang diselesaikan. Kuantitas yang diukur dari persepsi pegawai terhadap jumlah aktivitas yang ditugaskan beserta hasilnya.

2. Kualitas

Hasil Tingkat dimana hasil aktivitas yang dilakukan mendekati sempurna, dalam arti menyesuaikan beberapa cara ideal dari penampilan aktivitas, maupun memenuhi tujuan-tujuan yang diharapkan dari suatu aktivitas. Kualitas kerja diukur dari persepsi pegawai terhadap kualitas pekerjaan yang dihasilkan serta kesempurnaan tugas terhadap keterampilan dan kemampuan pegawai.

3. Kehadiran

Merupakan bentuk hasil dari aktivitas karyawan yang didukung dengan tingkat kehadiran dan ketepatan waktu yang tinggi.

4. Kemampuan bekerja sama

Kemampuan bekerja sama adalah karyawan dapat bekerja sama dengan pemimpin maupun rekan kerja agar tujuan efektivitas perusahaan tercapai dengan baik.

\section{Hipotesis Penelitian}

Hipotesis merupakan jawaban sementara terhadap objek yang akan diteliti mengacu kerangka pemikiran yang telah dipaparkan diatas menarik dugaan sementara bahwa :

H-1 :Diduga terdapat pengaruh yang positif dan signifikan antara Tingkat Pendidikan terhadap Kinerja karyawan pada PT Prima Makmur Rotokemindo.

H-2 :Diduga terdapat pengaruh positif dan signifikan antara Masa Kerja terhadap Kinerja karyawan pada PT Prima Makmur Rotokemindo.

H-3 :Diduga terdapat pengaruh yang positif dan signifikan anatara Tingkat Pendidikan dan Masa Kerja terhadap Kinerja Karyawan pada PT Prima Makmur Rotokemindo. 


\section{Metode Penelitian}

Pendekatan yang digunakan dalam penelitian ini adalah deskriptif kuantitatif dengan menggunakan angka-angka dan perhitungan dengan metode statistik, data-data diklarifikasikan dan dikategorikan dengan menggunakan table-table tertentu. Adapun tekniik analisis data dengan menggunkan analisis regresi sederhana, analisis varians dua arah dengan persyaratan analisis uji Kolmogorov-smirnov test, uji validitas dan realibilitas. Untuk mempermudah dalam menganalisis dengan menggunakan program SPSS for windos versi 23.0.

\section{Populasi dan Sampel}

Populasi dari penelitian ini adalah karayawan PT PRIMA MAKMUR ROTOKEMINDO yang berjumlah 297 orang karyawan tetap. Pengambilan sampel dalam penelitian ini dengan teknik probability sampling yaitu proportionate stratified random sampling dengan menggunakan rumus slovin. Menurut Sugiyono (2015:82).

$$
\begin{aligned}
& \mathrm{n}=\frac{242}{1+242 \cdot(0,1)^{2}} \\
& \mathrm{n}=\frac{242}{3_{3} 42}=70,76
\end{aligned}
$$

Jadi sample penelitian adalah 71 karayawan tetap di PT PRIMA MAKMUR ROTOKEMINDO.

Jenis Data

\section{Data Primer}

Data primer adalah data yang diperoleh secara langsung oleh peneliti yang berkaitan dengan variabel dalam penelitian. Data primer yang digunakan dalam penelitian ini berupa data variabel adalah tingkat pendidikan, masa kerja, kinerja karyawan.

2. Data Sekunder

Data sekunder yang digunakan dalam penelitian ini berupa karyawan tetap pada PT PRIMA MAKMUR ROTOKEMINDO. 


\section{Definisi Operasional Variabel}

Sedangkan teori yang digunakan sebagai alat ukur variabel tingkat pendidikan menggunakan teori Tirtarahardja (dalam Nur Afni, 2017 : 17) dengan dimensi:

1. Jenjang pendidikan

2. Kesesuaian jurusan

3. Kompetensi.

Sedangkan teori yang digunakan sebagai alat ukur variabel masa kerja menggunakan teoriIndah (Luh Maya Susanti, 2014 ) dengan dimensi :

1. Lama mengabdi

2. Kemampuan intelegensi

Sedangkan teori yang digunakan sebagai alat ukur variable kinerja karyawan menggunakan teori Anwar prabu mangkunegara (2013: 67) dengan dimensi :

1). Kuantitas,

2). Kualitas,

3).Kehadiran

4). Kemampuan.

\section{Uji Instrumen Penelitian}

\section{Uji Validitas}

Pengujian validitas dalam penelitian ini menggunakan bantuan aplikasi komputer SPSS Versi 23.0. Hasil pengujian dikatakan valid apabila nilai $r$ hitung > $\mathrm{r}$ tabel dan nilai signifikansi < tingkat signifikansi.Hasil uji validitas menunjukkan bahwa semua item pernyataan X1,X2 Dan Y memiliki nilai $\mathrm{r}$ hitung $>\mathrm{r}$ tabel $(0,194)$ dan nilai signifikansi< tingkat signifikansi $(0,01)$, sehingga dinyatakan bahwa keseluruhan item dalam instrumen penelitian ini adalah valid.

\section{Uji Reabilitas}

Dikatakan reliabel (layak) jika koefesien alpha cronbach's $>0,60$ dan dikatakan tidak reliabel jika koefesien alpha cronbach's $<0,60$. Hasil uji reabilitas menunjukkan bahwa semua variabel bebas dan terikat memiliki nilai koefesien Alpha Cronbach > 0,60 sehingga dapat dinyatakan bahwa instrument penelitian yang digunakan adalah reliable. 


\section{Uji Asumsi Klasik}

\section{Uji Normalitas}

Uji normalitas dalam penelitian ini dilakukan dengan analisi grafik normal P - plot. Hasil uji normalitas menggunakan grafik normal P-Plot menunjukkan bahwa terlihat data (titik) menyebar disekitar garis diagonal dan penyebarannya mengikuti garis diagonal, maka model regresi yang digunakan dalam penelitian ini terdistribusi normal.

\section{Uji Multikolonieritas}

Berdasarkan uji multikolonieritas dapat diketahui bahwa masing-masing variabel bebas menunjukkan nilai VIF tidak lebih dari 10, maka asumsi tidak terjadi multikolonieritas telah terpenuhi.

\section{Uji Heteroskedastitas}

Uji heteroskedastitas dalam penelitian ini dilakukan dengan menggunakan grafik scatterplot antara variabel dependen (SRESID) dan Variabel residualnya (ZPRED). Grafik ini menunjukkan pola penyebaran titik - titik. Jika titik - titik menyebar diatas dan dibawah 0 pada sumbu Y. Berarti tidak terjadi heteroskedastitas pada data yang akan digunakan. Berdasarkan grafik scatterplot tersebut terlihat bahwa titik - titik menyebar secara acak serta tersebar baik diatas maupun dibawah angka 0 pada sumbu $Y$. sehingga dapat disimpulkan bahwa tidak terjadi heteroskedastitas pada model regresi.

\section{Analisis Regresi Linier Berganda}

Model regresi yang digunakan yaitu Unstandardized Coefficients, karena data yang digunakan dalam penelitian ini adalah data interval yang pengukurannya menggunakan skala Likert. Hasil analisis regresi linier berganda yang didapatkan dengan menggunakan aplikasi computer SPSS versi 23.0 adalah sebagai berikut:

$\mathrm{Y}=0,335 \mathrm{X} 1+0,537 \mathrm{X} 2$

Dimana :

Y : Kinerja Pegawai

$\mathrm{X} 1$ : Tingkat Pendidikan

$\mathrm{X} 2$ : Masa Kerja

$\mathrm{Y}=12.348+0,698 \mathrm{X}_{1}+0,092 \mathrm{X}_{2}$

Sesuai dengan persamaan regresi yang diperoleh, maka model regresi tersebut dapat di interpretasikan sebagai berikut : 
a. Koefisien konstanta sebesar 12.348, hal ini berarti jika nilai dari tingkat pendidikan $\left(\mathrm{X}_{1}\right)$ dan masa kerja $\left(\mathrm{X}_{2}\right)$ sama dengannilainol, maka tingkat atau besarnya kinerja karyawan (Y) sebesar 12.348.

b. Koefisien regresi variabel tingkat pendidikan $\left(\mathrm{X}_{1}\right)$ sebesar 0,698 artinya jika variabel bebas lainnya tetap dan masa kerja $\left(\mathrm{X}_{2}\right)$ mengalami kenaikan, maka kinerja karyawan (Y) akan mengalami peningkatan sebesar 0,698. Koefisien ini terjadi pengaruh yang signifikan antara tingkat pendidikan terhadap kinerja karayawan.

c. Koefisien regresi variabel masa kerja $\left(\mathrm{X}_{2}\right)$ sebesar 0,092 artinya jika variabel independent lain nilainnya tetap dan tingkat pendidikan $\left(\mathrm{X}_{1}\right)$ mengalami kenaikan, maka kinerja karayawan (Y) akan mengalami peningkatan sebesar 0,092. Koefisien ini terjadi pengaruh yang signifikan antara masa kerja terhadap kinerja karyawan.

\section{Koefesien Determinasi (R2)}

Dari perhitungan diatas diperoleh nilai koefisien determinasi berganda $\left(\mathrm{R}^{2}\right)$ adjusted sebesar 0,727 . Hal ini dapat diartikan bahwa variabel tingkat pendidikan dan masa kerja mempengaruhi72,7\% terhadap kinerja karyawan. Nilai koefisien determinasi ini menunjukan tingkat hubungan variabel $\mathrm{X}_{1}$ dan $\mathrm{X}_{2}$ terhadap $\mathrm{Y}$ adalah sangat besar dan sisanya sebesar $27,3 \%$ di pengaruh faktor lain.

\section{Hasil Penelitian dan Pembahasan}

\section{Hipotesis Pertama dan Kedua}

Dasar pengambilan keputusan uji t, yaitu:

1. Jika $\mathrm{t}$ hitung $<\mathrm{t}_{\text {tabel }}$ atau $-\mathrm{t}_{\text {tabel }}<\mathrm{t}$ hitung $\left(\mathrm{H}_{0}\right.$ diterima: tidak ada pengaruh signifikan).

2. Jika $\mathrm{t}$ hitung $>\mathrm{t}_{\text {tabel }}$ atau $-\mathrm{t}_{\text {hitung }}<-\mathrm{t}$ tabel $\left(\mathrm{H}_{0}\right.$ ditolak: ada pengaruh signifikan)

Nilai $t_{\text {hitung }}$ tingkat pendidikan adalah 13.358> 1,29394 $t_{\text {tabel }}$ dan nilai signifikansinya adalah sebesar $0,000<0,01$. Maka dapat disimpulkan bahwa Ho ditolak dan $\mathrm{H}_{2}$ yang artinya tingkat pendidikan $\left(\mathrm{X}_{1}\right)$ berpengaruh positif dan signifikan terhadap kinerja karyawan (Y), dengan demikian nilai tingkat pendidikan akan semakin meningkat, maka kinerja karyawan (Y) akan semakian meningkat. Semakin tinggi tingkat pendidikan maka semakin baik kinerjanya, begitu juga sebaliknya semakin rendah pendidikan mengakibatkan tinggak produktifitas semakin rendah.

Nilai $t_{\text {hitung }}$ masa kerja $\left(\mathrm{X}_{2}\right)$ adalah 2,023> 1,29394 $\mathrm{t}_{\text {tabel }}$ dan nilai signifikansinya adalah sebesar $0,047<0,01$. Maka dapat disimpulkan bahwa 
Ho ditolak dan $\mathrm{H}_{2}$ diterima yang artinya masa kerja $\left(\mathrm{X}_{2}\right)$ berpengaruh positif dan signifikan terhadap kinerja karyawan (Y), dengan demikian nilai masa kerja akan semakin meningkat, maka kinerja karyawan (Y) akan semakian meningkat. Tingkat pengalaman seseorang karyawan akan berpengaruh terhadap kinarja karyawan, semakin lama bekerja akan meningkatkan kinerja dan produktifitas karyawan.

\section{Hipotesis Ketiga}

Uji signifikansi simultan dilakukan dengan menggunakan uji $\mathrm{F}$ dengan kriteria pengujian sebagai berikut :

a. Jika F hitung < F tabel dan nilai signifikansi > tingkat signifikansi maka tidak ada pengaruh yang sigifikan dari variabel bebas secara simultan terhadap variabel terikat.

b. Jika F hitung > F tabel dan nilai signifikansi < tingkat signifikansi maka terdapat pengaruh signifikan dari variabel bebas secara simultan terhadap variabel terikat.

Semakin tinggi tingkat pendidikan dan semakin lama karyawan tersebut bekerja di suatu perusahan maka produktifitas yang akan di peroleh perusahaan akan semakin baik.

ANOVA $^{\mathrm{a}}$

\begin{tabular}{|ll|r|r|r|r|r|}
\hline Model & & Sum of Squares & Df & Mean Square & F & \multicolumn{1}{c|}{ Sig. } \\
\hline 1 & Regression & 274.430 & 2 & 137.215 & 90.335 & $.000^{\mathrm{b}}$ \\
& Residual & 103.289 & 68 & 1.519 & & \\
& Total & 377.718 & 70 & & & \\
\end{tabular}

a. Dependent Variable: Kinerja Karyawan (Y)

b. Predictors: (Constant), Masa Kerja $\left(\mathrm{X}_{2}\right)$, Tingkat Pendidikan $\left(\mathrm{X}_{1}\right)$

Berdasarkan tabel hasil perhitungan Statistik uji $\mathrm{F}$ diatas, menunjukkan nilai F-hitung > F-tabel yaitu 90.335> 4,93 maka dapat disimpulkan bahwa Ho ditolak dan $\mathrm{H}_{3}$ diterima, Artinya tingkat pendidikan $\left(\mathrm{X}_{1}\right)$ dan masa kerja $\left(\mathrm{X}_{2}\right)$ secara bersama-sama berpengaruh positif dan signifikan terhadap kinerja karyawan (Y), dengan demikian nilai tingkat pendidikan dan masa kerja secara bersama-sama akan semakin meningkat, maka kinerja karayawan akan semakin meningkat. 


\section{Kesimpulan dan Saran \\ Kesimpulan}

Berdasarkan hasil analisis dan pembahasan, tentang rekrutmen dan pengembangan karyawan terhadap Kinerja karyawan pada PT PRIMA MAKMUR ROTOKEMINDO, penulis menarik kesimpulan sebagai berikut :

1. Tingkat pendidikan $\left(\mathrm{X}_{1}\right)$ berpengaruh positif dan signifikan dari hasil koefisien regresi sebesar 0,698 sehingga dapat dikatakan bahwa tingkat pendidikan $\left(\mathrm{X}_{1}\right)$ berpengaruh positif dan signifikan terhadap kinerja karyawan (Y) pada PT PRIMA MAKMUR ROTOKEMINDO.

2. Masa kerja $\left(\mathrm{X}_{2}\right)$ berpengaruh rendah dan signifikan secara dari hasil koefisien regresi sebesar 0,092 sehingga dapat dikatakan bahwa masa kerja $\left(\mathrm{X}_{2}\right)$ berpengaruh positif dan signifikan terhadap kinerja karyawan (Y) pada PT PRIMA MAKMUR ROTOKEMINDO.

3. Tingkat pendidikan dan masa kerja berpengaruh positif dan signifikan sebesar $72,7 \%$ secara simultan pada PT PRIMA MAKMUR ROTOKEMINDO.

\section{Saran}

Berdasarkan dari kesimpulan di atas, maka penulis dapat memberikan saran-saran sebagai berikut :

A. Bagi Perusahaan

1. Pada prinsipnya tingkat pendidikan $\left(\mathrm{X}_{1}\right) \mathrm{PT}$ Prima Makmur Rotokemindo kondisinya telah baik karena rata-rata skor 293.4. agar tingkat pendidikan menjadi sngat baik, yang perlu ditingkatkan menurut hasil dari rekaptulasi tingkat pendidikan adalah skor yang terkecil 264 dari indikator (TP.06) yaitu kurangnyaa karayawan memiliki keahlian seperti yang di butuhkan perusahaan. Agar karyawan dapat mengasah keahliannnya maka perusahaan harus memberikan karyawan pelatihan sebagai bekal ilmu karyawan untuk menguasai bidang yang ditekuni atau sebagai motif untuk berjaga-jaga apabila terdapat rotasi pekerjaan. Dan skor paling tinggi adalah 312 dari indikator (TP.06) yaitu karyawan memiliki keahlian seperti yang dibutuhkan perusahaan

2. Pada prinsipnya masa kerja $\left(\mathrm{X}_{2}\right)$ PT Prima Makmur Rotokemindo kondinya baik dengan rata-rata 265,1. Agar masa kerja menjadi sangat baik, yang perlu ditingkatkan menurut hasil dari rekaptulasi masa kerja adalah skor yang terkecil 230 dari indikator (MS.06) yaitu kurangnya kemahiran karyawan dalam melaksanakan tugas, untuk itu karyawan harus selalu bisa mengurangi kesalahan pada saat melaksanakan pekerjaan. Dan skor paling tinggi adalah 314 dari indikator (MS.01) yaitu pengalaman yang dimiliki karyawan membantu mengurangi kesalahan pekerjaan. 
3. Pada prinsipnya kinerja karyawan (Y) PT Prima Makmur Rotokemindo kondisinya sangat baik karena rata-rata skor 309,14. Agar kinerja karyawan bertahan sangat baik, yang perlu ditingkatkan menurut hasil dari rekaptulasi kinerja karyawan adalah skor 287 yang terkecil (KK.07) yaitu kurangya rasa berusaha menyelesaikan tugas dengan penuh rasa tanggung jawab dan kecakapan. Maka pimpinan harus memotivasi karyawan agar meningkatkan kesungguahan dalam bekerja agar tercapainya kinerja karyawan yang tinggi. Dan skor paling tinggi 324 indikator (KK.03) yaitu karyawan selalu menjaga kerapihan dan ketepatan dalam bekerja.

B. Bagi Perusahaan

Bagi PT Prima Makmur Rotokemindo, diharapkan agar lebih meningkatkan kinerja karyawan melalui tingkat pendidikan, karena penelitian membuktikan bahwa tingkat pendidikan dapat mempengaruhi kinerja karyawan. Adapun cara agar dapat meningkatkan kinerja karyawan melalui tingkat pendidikan yaitu memperhatikan karyawan dengan tingkat pendidikan yang tinggi. Di samping tingkat pendidikan, faktor masa kerja juga perlu diperhatian. Adapun langkah dalam peningkatan masa kerja dengan memperhatikan masa kerja yang dimiliki oleh karyawan dalam meningkatkan kinerja karyawan. Hubungan antara karyawan dengan rekan kerjanya perlu mendapatkan perhatian guna menghindari ketidakharmonisan hubungan dengan rekan sekerja

\section{Bagi Peneliti Selanjutnya}

Bagi peneliti selanjutnya yang tertarik untuk mengkaji aspek yang serupa yaitu tingkat pendidikan, masa kerja, serta kinerja karyawan diharapkan untuk mengembangkan penelitian ini dengan menggunakan populasi yang lebih luas agar hasil penelitian lebih teruji keandalannya, disamping itu juga diharapkan untuk menguji variabel lain yang diduga kuat dapat mempengaruhi kinerja karyawan seperti iklim organisasi, kepemimpinan, kemampuan kerja, dan disiplin kerja.

\section{Daftar Pustaka}

Buku:

Ghozali, Imam (2013) Aplikasi analisis multivariate dengan program SPSS. Yogyakarta :BP Universitas Diponegoro Edisi 7

Hasibuan, Melayu S.P. (2007) manajemen personalia dan sumber daya manusia. Jakarta : PT. Bumi Askara

Mangkunegara P Anwar(2013) manajemen sumber daya manusiaperusahaan, cetaakan kesebelas. Bandung :PT Remaja Rosdakarya 
Rasmawati, Idri Novi. (2016) "Pengaruh tingkat pendidikan dan kompensasi terhadap kinerja karyawan pada PT Krakatau Steel (PERSERO)Tbk. Divisi CRM (COLD ROLLING MILL)" : Skripsi FE Universitas Serang Raya

Ridwan,M. B. dan Sunarto, M,Si. (2017) Pengantar statistika untuk penelitian pendidikan,sosial,komunikasi,ekonomi. Bandung : Alfabeta

Sugiyono, (2015), Cetakan ke-22 (2015).Metode penelitian Kuantitatif dan R\&D,Alfabeta, Bandung

Suparyadi, (2015) Manajemen sumber daya manusia. Yogyakarta : CV Andi Offset

Tayfini, Nur Afni. (2017) "Pengaruh tingkat pendidikan dan kepercayaan diri terhadap kualitas kerja karyawan PT. Kolon Ina" : Skripsi FE Universitas Serang Raya

Yani, M. H. (2012) manajemen sumber daya manusia. Jakarta :Mitra Wacana Media,2012

\section{JURNAL :}

Dewi, Desak Ketut Ratna. Suwendra, I Wayan. Yulianthini, Ni Nyoman. (2016) "Pengaruh tingkat pendidikan dan motivasi kerja terhadap kinerja karyawan" : E- Jurnal Manajemen, [online] Vol.4, No 1. Tersedia : http://id.portalgaruda.org/[ 04 februari 2018]

Dewi, Micheliana (2016) "Hubungan Tingkat Pendidikan dan Masa Kerja dengan Kepatuhhan penggunaan Safety Helmet pada pekerja”, [online]. Tersedia: http://eprints.uns.ca.id

Dwi Kurniawati, Irma. (2014) "Masa kerja Dengan Job Engagement pada karyawan".ejournal.umm.ac.id [online] Vol 02, NO.02. Tersedia :https://scholar.google.com/scholar/[22 desember 2017]

Hardikriyawan, Aldi. (2015) "Pengaruh pelatihan dan masa kerja terhadap kinerja pegawai (studi pada kantor Badan Pusat Statistik Kota Probolinggo)" : E- Jurnal FEB, [online] Vol.3, No 1. Tersedia : http://id.portalgaruda.org/[ 04 februari 2018]

Komaling, J Helena . dkk . (2016) "Pengaruh rekrutmen, motivasi dan lingkungan kerja terhadap kinerja pegawai PT BRI cabang Manado".: Jurnal berkala ilmiyah [online] Vol. 16 No 01. Tersedia : http://id.portalgaruda.org/[02 februari 2018]

Mamahit, Rendy. (2013) "Tingkat pendidikan, pelatihan, dan kepuasan kerja pengaruhnya terhadap kinerja pegawai di Badan Penanggulangan Bencana Provinsi Sulawesi Utara" : E- Jurnal Riset Ekonomo, Manajemen, Bisnis dan Akuntansi [online] Vol.1, No4. Jurnal EMBA, 936-1053. Tersedia : http://id.portalgaruda.org/[ 04 februari 2018] 
Muttaqin, Muttaqin. Nuridja, I Made. Tripalupi, Lulup Endah. "Pengaruh latar belakang pendidikan, masa kerja dan motivasi kerja karayawan terhadap kinerja karyawan pada PT. Indocitra Jaya Samudra tahun 2013” : E- Jurnal Pendidikan Ekonomi, [online] Vol.4, No 1. Tersedia : http://id.portalgaruda.org/[ 04 februari 2018]

Nasution, Masnun Zaini. Darmayanti,Nefi. (2011) "Pengaruh latar belakang pendidikan dan masa kerja terhadap kinerja guru Raudhatul Athfal" : E- Jurnal ANALITIKA, [online] Vol.3, No 1. ANALATIKA Juni, 3743. Tersedia : http://id.portalgaruda.org/[ 05 februari 2018]

Septarina, Mifta. (2017) "Pengaruh tingkat pendidikan dan lamanya bekerja terhadap kinerja karayawan pada PT Pegadaian Syariah Simpang Patal Palembang": E- Jurnal Bisma Universitas Pendidikan Ganesha, [online] Vol 4. Tersedia : http://epirints.radenfatah.ac.id/[04 februari 2018]

Sinthia Dewi,. I.Wayan Bagia, Gede Putu Agus Jana. (2016) "Pengaruh tingkat pendidikan dan pengembangan karir terhadap kinerja karyawan" : E- Jurnal Manajemen, [online] Vol.4, No 1. Tersedia : http://id.portalgaruda.org/[ 04 februari 2018]

Sri Hariyanti, Setyani. (2010) "Pengaruh tingkat pendidikan, lingkungan kerja dan masa kerja terhadap kinerja kepala sekolah SMP NEGERI Sekabupaten Karanganyar dengan gender sebagai variabel moderator" : E- Jurnal PROBANK, [online] Vol.18, No 10. Tersedia : http://id.portalgaruda.org/[ 04 februari 2018]

Susanti, Luh Maya. (2014) "Pengaruh pelatihan, insentif, dan masa kerja terhadap kinerja karyawan PT PLN (Studi pada PT PLN Persero distribusi Jatim area Malang)" : E- Jurnal Ilmiah Mahasiswa FEB, [online] Vol2, No 1. Tersedia : http://id.portalgaruda.org/[ 05 februari 2018]

Wirawan, Ketut Edy. Bagia, I Wayan. Susila, Gede Putus Agus Jana. (2014) "Pengaruh tingkat pendidikan dan pengalaman kerja terhadap kinerja karyawan" : E- Jurnal Manajemen, [online] Vol.2, No 2. Tersedia : http://id.portalgaruda.org/[ 04 februari 2018] 